\title{
Tracking infectious diseases in cyberspace
}

$\mathrm{C}$ all it next-generation zoonotic sleuthing.

Basically, it involves the collection of online data from thousands of sources, including stories from news aggregators like Google News, reports from international health agencies, personal accounts and the musings of online discussion groups. Those data are integrated with field surveillance information about wildlife trade and wild animal hunting into a Web-based, open-access system called HealthMap .org/predict that proponents hope will provide real-time intelligence about emerging pathogens.

"The real focus is identifying and focusing surveillance in hot spots around the world where we have potential for risk of a new disease that potentially might cause a pandemic worldwide," says John Brownstein, cofounder of HealthMap.org and assistant professor of pediatrics at the Harvard Medical School in Boston, Massachusetts.

The inclusion of such surveillance data from South East Asia, Central Africa and Latin America will help to "test the hypothesis that wildlife trade increases risk of zoonotic disease emergence," Cheryl Chetkiewicz, associate conservation scientist at Wildlife Conservation Society, writes in an email. The society is one of five institutions, along with the University of California School of Veterinary Medicine, EcoHealth Alliance, Global Viral Forecasting Inc. and the Smithsonian Institution that are implementing the Predict warning system as part of the HealthMap initiative.

The Predict system was created by the United States Agency for International Development's (USAID) Emerging Pandemics Threats Program in 2009 to bolster global capacity to identify pathogenic threats.

Damien Joly, the Wildlife Conservation Society's associate director for wildlife health monitoring and epidemiology, says the integration of online and field surveillance data is key. "There are

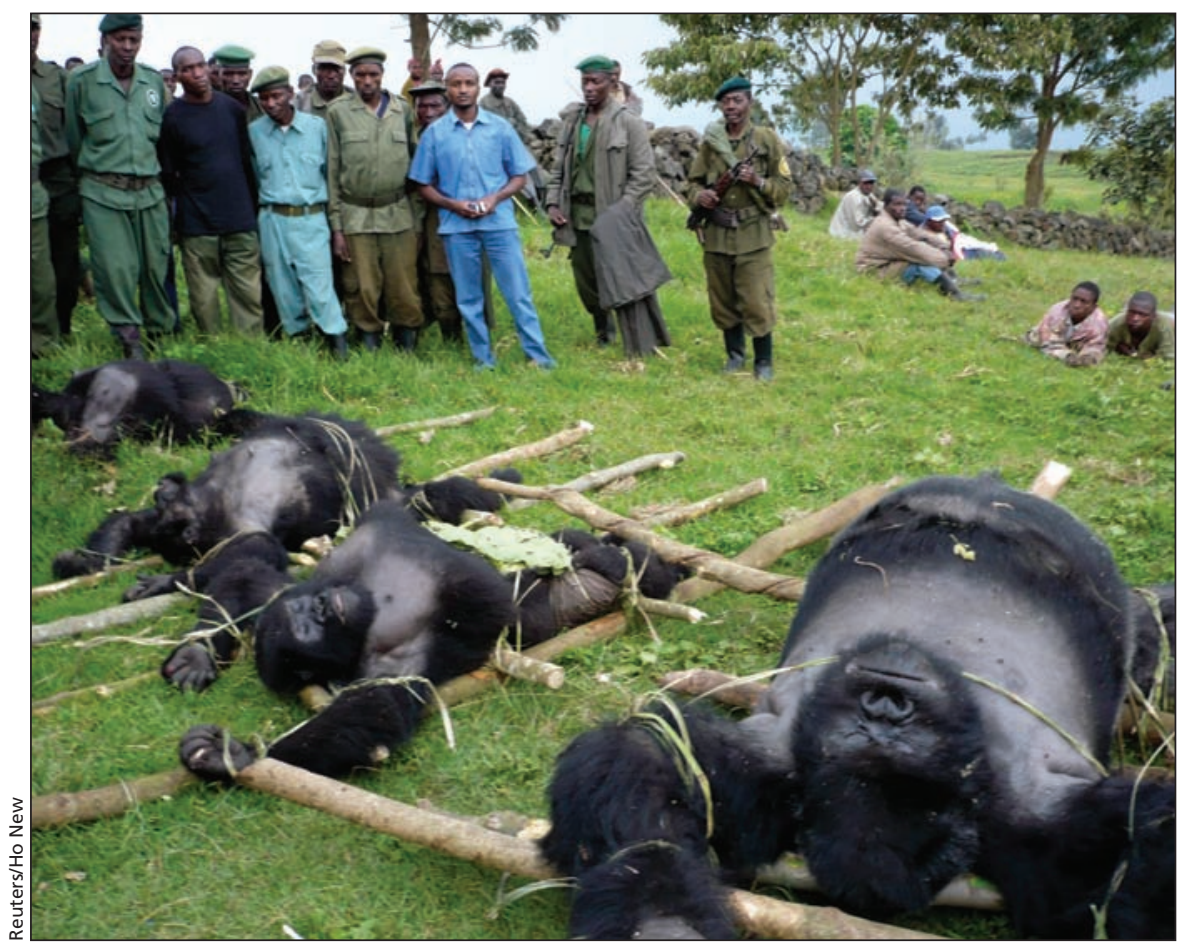

A newly developed sleuthing tool to identify emerging pathogens will incorporate field surveillance data about wildlife trade, wild animal hunting and poaching, which led to the illegal killing of four mountain gorillas in the Virunga National Park in the Democratic Republic of Congo, depicted above.

newspapers all over the planet, so we take advantage of their reporting to understand disease emergence or detect disease emergence."

"There's a connection between what we can find on the Web and what people are seeing on the ground," Brownstein says, adding that a feedback loop allows for validation of data.

The field surveillance data is obtained by a USAID-funded project that allows field samples to be collected in more than 20 countries in four epidemiological hot spot regions: the Amazon Basin, Congo Basin, Gangetic Plains (India and Bangladesh) and South East Asia.

Although gaps in data collection will be inevitable unless all countries of the world participate, proponents say they're making a good start on the creation of a global surveillance system.

"Obviously there're many places that are missing and down the road those would get filled in, but I think this does represent a very good sampling of places where we have significant risk," Brownstein says.

The primary users of the site are initially projected to be the World Health Organization, as well as other public health agencies such as the US Centers for Disease Control, Brownstein says. "More and more we've realized that [HealthMap] plays a critical resource for national and international public health agencies and they're using it for day-today activities so that definitely gives us a mandate to keep doing this.'

But the site is "also being used by the general population and travellers and other people that want to keep up with what's happening around the world in real-time, where they might not find that information elsewhere," he adds.

Brownstein argues the system will also better inform people about the 
ubiquitous nature of infectious diseases, and the need for vaccinations. "We're trying to communicate that infectious diseases are happening everywhere. They're happening in your neighbourhood, not just something that is foreign, something somewhere else."

Barriers to widespread use include the need for Internet access, which is not always available in developing countries.

HealthMap is among a number of new cyber tools being used for public health detection, Brownstein says. Others include a Smartphone application, "Outbreaks Near Me," that provides real-time disease outbreak data and offers users an opportunity to report on outbreaks (www.healthmap .org/outbreaksnearme/).

"It doesn't serve public health when you're sitting on data that could be out in the open and used to respond to an emerging disease event," Joly says. Adrianna Banaszek, Ottawa, Ont.

CMAJ 2011. DOI:10.1503/cmaj.109-3829 